\title{
Risk-Targeted Behavioral Activation for the Management of Work-Disability Associated with Co- Morbid Pain and Depression: A Feasibility Study
}

Michael Sullivan ( $\square$ michael.sullivan@mcgill.ca )

McGill University https://orcid.org/0000-0002-4228-1678

Timothy H. Wideman

McGill University

Nathalie Gauthier, Ph.D.

CCCF

Pascal Thibault

McGill University

Tamra Ellis

Centre for Rehabilitation and Health

Heather Adams

University Centre for Research on Pain and Disability

Research

Keywords: pain, depression, musculoskeletal, rehabilitation

Posted Date: January 3rd, 2022

DOI: https://doi.org/10.21203/rs.3.rs-1211828/v1

License: (c) (i) This work is licensed under a Creative Commons Attribution 4.0 International License.

Read Full License 


\section{Abstract \\ Purpose}

The purpose of the present study was to conduct a preliminary evaluation the feasibility and impact of a risk-targeted behavioral activation intervention for work-disabled individuals with co-morbid pain and depression.

\section{Methods}

The design of the study was a single arm non-randomized trial. The sample consisted of 66 workdisabled individuals with co-morbid pain and depression. The treatment program consisted of a 10-week standardized behavioral activation intervention supplemented by techniques to target two psychosocial risk-factors for delayed recovery, namely, catastrophic thinking and perceptions of injustice. Measures of pain severity, depression, catastrophic thinking, perceived injustice and self-reported disability were completed pre-, mid-, and post-treatment. Satisfaction with treatment was assessed at post-treatment. Return to work was assessed at 6-month follow-up.

\section{Results}

The drop-out rate was $18 \%$. At treatment termination, $91 \%$ of participants indicated that they were 'very' or 'completely' satisfied with their involvement in the treatment program. Significant reductions in pain $(d=$ .71), depression ( $d=.86)$, catastrophic thinking $(d=1.1)$ and perceived injustice $(d=1.0)$ were observed through the course of treatment. In multivariate analyses, treatment-related reductions in depression, catastrophic thinking, perceived injustice, but not pain, contributed significant unique variance to the prediction of return-to-work outcomes.

\section{Conclusions}

Risk-targeted behavioral activation was found to be an acceptable and effective intervention for workdisabled individuals with co-morbid pain and depression. The findings suggest that interventions targeting psychosocial risk factors for pain and depression might contribute to more positive recovery outcomes in work-disabled individuals with co-morbid pain and depression.

\section{Key Messages Regarding Feasibility}

1. There is currently little evidence about intervention approaches that contribute to occupational reengagement in work-disabled individuals with co-morbid pain and depression. 
2. The results of this study provide preliminary evidence for the acceptability and effectiveness of RiskTargeted Behavioral Activation (RTBA) as an approach to promoting successful occupational reengagement in work-disabled individuals with co-morbid pain and depression.

3. The finds warrant proceeding to a randomized clinical trial to assess the efficacy of RTBA as an approach to fostering occupational re-engagement in work-disabled individuals with co-morbid pain and depression.

\section{Background}

Work-related musculoskeletal disorders (WRMD) are a leading cause of disability [1]. In North America, WRMDs rank among the most expensive non-malignant health conditions affecting the working-age population [1]. Depression has been identified as a risk factor for problematic recovery outcomes of WRMDs [2, 3]. Depressive symptoms contribute to lower productivity and extended periods of sick leave in individuals with WRMDs [3-5]. Depressive symptoms have also been associated with longer duration of salary indemnity benefits following work injury or surgical intervention [6, 7]. Estimates of the prevalence of clinically significant depression associated with work-related musculoskeletal pain range from $20-40 \%$, thus making the effective management of disability associated with co-morbid pain and depression a pressing clinical concern $[8,9]$.

Traditional approaches to the clinical management of co-morbid musculoskeletal pain and depression have included referrals to mental health services for pharmacotherapeutic or psychotherapeutic treatment, or the provision of psychological services within multidisciplinary pain programs [10-13]. While symptomatic treatment is an important component of the clinical management of pain and depression, the results of several investigations suggest that symptom-focused interventions, whether aimed at reducing symptoms of pain or depression, yield only modest reductions in work-disability [1416]. Some symptom-focused interventions, such as the use of opioids for the treatment of persistent pain, have actually been shown to contribute to longer periods of work-disability (Volin et al., 2009). It has been suggested that reducing disability-relevant risk factors associated with pain and depressive symptoms might lead to more positive return-to-work outcomes than interventions that focus exclusively on symptom reduction [16-19]. To date, research has yet to address the impact of risk-targeted treatment on work-disabled individuals with co-morbid pain and depression.

The present study examined the feasibility of a 10-week standardized risk-targeted behavioral activation (RTBA) intervention designed to promote occupational re-engagement in work-disabled individuals with co-morbid pain and depression. Behavioral activation is an evidence-based treatment for depression focusing on goal setting, activity scheduling and problem solving [20]. The behavioral activation intervention was supplemented with techniques specifically designed to reduce psychosocial risk factors for prolonged work-disability, namely catastrophic thinking and perceived injustice. Catastrophic thinking refers to the tendency to anticipate the worst possible outcomes of one's health or mental health condition [21]. Perceived injustice has been conceptualized as an appraisal process characterized by a tendency to construe one's losses as severe and irreparable, and to attribute blame to others for one' 
suffering [22]. High scores on measures of catastrophic thinking and perceived injustice have been shown to prospectively predict more intense symptoms of pain and disability, and more prolonged periods of work absence [23-25].

Of interest was to determine 1) whether the RTBA intervention was acceptable to participants, 2) whether participants were satisfied with the RTBA intervention, 3) whether the RTBA intervention yielded meaningful reductions in symptom severity and disability-relevant psychosocial risk factors, 4) whether the RTBA intervention yielded meaningful reduction in occupational disability, and 5) to identify the treatment-related changes most predictive of occupational re-engagement.

\section{Method}

\section{Participants}

The initial sample consisted of 66 work-disabled individuals ( 15 women, 51 men) with musculoskeletal pain and depression. The study sample was recruited through local media advertisements. The media advertisements solicited individuals who had sustained a musculoskeletal injury to the back or neck and were currently absent from work. The inclusion criteria were as follows: 1) work-disability greater than 4 weeks associated with a musculoskeletal injury to the back or neck, 2) a score above clinical threshold on a self-report measure of depression, and 3) between 25 and 55 years of age. Participants who met inclusion criteria for the study were invited to watch an introductory video that provided detailed information about the procedures (i.e., behavioral activation) and the goals (i.e., return to work) of the RTBA intervention. Participants received $25 \$$ for each session of the intervention program they attended. Compensation was provided to defray the costs of inconveniences (e.g., travel, childcare) that might be associated with participation.

Risk-Targeted Behavioral Activation (RTBA). Behavioral activation is a structured approach to treatment that was originally developed for the treatment of depression [20]. Numerous investigations have supported the use of behavioral activation as an effective treatment for depression [26]. There are also indications that behavioral activation might improve return to work outcomes in individuals with chronic depression [27]. The behavioral activation component of the treatment program focused on goal setting, structuring and scheduling activities, increasing success and achievement experiences, and problemsolving. In order to maximize the impact of behavioral activation on disability reduction, goal setting and scheduling of activities focused primarily on resumption of discontinued activities as opposed to focusing on the scheduling of pleasant activities. One objective of goal setting and activity scheduling was to reduce the discrepancy between the client's pre-injury activity repertoire and the client's current activity repertoire.

Behavioral activation was supplemented by a collection of techniques designed to reduce catastrophic thinking and perceptions of injustice, two psychosocial risk factors that have been shown to contribute to prolonged work-absence $[19,25]$. Techniques for reducing catastrophic thinking included education, guided disclosure, and increasing behavioral flexibility. Techniques for reducing perceptions of injustice 
included validation, identifying sources of the client's perceptions of injustice, and injustice-focused problem-solving. The intervention also involved engaging with the primary care professional, the case manager and the employer to collaborate on the development of a safe and sustainable return-to-work plan.

Participants first viewed an introductory video providing an overview of the procedures and objectives of the treatment program. The content of the video clearly identified return-to-work as a central objective of the treatment program. A client workbook was used for activity scheduling and to guide participants through exercises aimed at reducing catastrophic thinking and perceived injustice. Clinicians met individually with participants once per week for a total of 10 weeks. The clinicians for the study included 10 rehabilitation professionals (9 occupational therapists, 1 physiotherapist). All clinicians followed a two-day training workshop to acquire the skills necessary to deliver the intervention. All clinicians received weekly supervision by a senior clinician with extensive experience in risk-targeted behavioral activation.

\section{Measures}

Pain Severity. The McGill Pain Questionnaire Short-Form (MPQ-SF) was used to measure pain severity [28]. Participants rated their current pain experience according to 15 pain descriptors on severity scale with the anchors (0) none, (1) mild, (2) moderate, or (3) severe. Scores range from 0 to 45 where higher scores represent more severe pain. The measure has been shown to be reliable and valid in various clinical populations $[29,30]$.

Depressive symptoms. The Patient Health Questionnaire-9 (PHQ-9) was used to assess depressive symptom severity. On this measure, respondents indicate how frequently they experience each of 9 symptoms of depression. Ratings are made on a 4-point frequency scale with the endpoints (0) 'not at all' and (3) 'everyday. PHQ-9 scores can range from 0 to 27 with higher scores indicating more severe depressive symptoms. A PHQ-9 score of 10 (i.e., moderate depression) was used as the criterion for clinically significant depression. The reliability and validity of this measure have been established in several different clinical samples [31, 32].

Pain Catastrophizing. The Pain Catastrophizing Scale (PCS) was used to assess catastrophic thinking related to pain [33]. The PCS consists of 13 items describing different thoughts and feelings that individuals might experience when they are in pain. The PCS has been shown to have high internal consistency (coefficient alpha $=.87$ ) and to be associated with heightened pain, emotional distress, disability as well as employment status [34-36].

Perceived injustice. The Injustice Experiences Questionnaire (IEQ) was used to measure injury-related perceptions of injustice [22]. The IEQ consists of 12 items assessing a range of injury-related injustice appraisals. The IEQ has been shown to have high internal consistently and test-retest reliability, and to be associated with prolonged occupational disability in individuals with musculoskeletal pain $[17,22]$. 
Self-Reported Disability. The Pain Disability Index (PDI) [37] was used to assess self-rated disability. Respondents rated their level of disability in 7 different areas of daily living (home, social, recreational, occupational, sexual, self-care, life support) due to their pain. The PDI has been shown to be internally reliable and significantly correlated with objective indices of disability [38].

Return to Work. Return to work status was assessed by telephone interview at 6-month follow-up. Participants responded to a number of employment-related questions including whether they have returned to full-time work, part-time work, transitional work or whether they remained occupationally disabled.

Acceptability of treatment. The degree of acceptability of the treatment program was assessed by computing a) the proportion of respondents who agreed to watch the introductory video, b) the proportion of respondents who agreed to participate after watching the introductory video, and c) the proportion of patients who completed the treatment program.

Treatment satisfaction. Satisfaction with participation in the intervention program was recorded using a 5-point numerical scale with the verbal anchors (0) not at all satisfied, (1) somewhat satisfied, (2) moderately satisfied, (3) very satisfied, and (4) completely satisfied.

\section{Procedure}

This study was approved by Institutional Review Board of McGill University. During an initial telephone screening interview, participants responded to the two questions that comprise the PHQ2. Participants who scored above clinical threshold on the PHQ-2 during the screening interview, and on the PHQ-9 at the pre-treatment assessment (approximately 2 weeks later), were considered to be experiencing clinically significant symptoms of depression [39, 40]. All participants were enrolled in the treatment program between January 2016 and December 2017. The intervention was offered as a complement to any other pharmacological or physical interventions that might have been prescribed for symptom management. Study measures were completed at pre-, mid- and post-treatment. Treatment satisfaction was only assessed at post-treatment.

\section{Data Analytic Approach}

Descriptive statistics were computed on all study variables. Tests of mean differences were used to compare pre- and post-treatment scores on outcome measures. Percentage change values were computed on measures of symptom severity and psychosocial risk in order to address the clinical significance of treatment-related changes. Correlational analyses were conducted to examine interrelations among indices of change. A logistic regression was used to address the role of treatment-related changes in psychosocial risk measures as determinants of return-to-work outcomes.

Five participants returned to work prior to completing all 10 sessions of the treatment program. For these participants, mid-treatment assessment results were carried forward and used as their post-treatment 
evaluation. Participants who completed fewer than 10 sessions and did not return to work were considered to have prematurely terminated the intervention (i.e., dropped out).

\section{Results}

\section{Treatment Acceptability}

A total of 69 individuals meeting selection criteria for the study responded to the study advertisements. Following a screening interview and having been provided with an explanation of the objectives of the study, $95 \%(n=66)$ agreed to watch the introductory video. Of the 66 individuals who agreed to watch the introductory video, all agreed to enroll as a participant in the study.

Twelve participants (18\%) prematurely terminated the intervention. The main reasons for premature termination included: 1$)$ not interested $(n=5), 2)$ accessibility challenges $(n=3), 3)$ another injury or a medical procedure $(n=2), 4)$ no reason provided $(n=2)$. Of the participants who completed the treatment program $(\mathrm{N}=54), 91 \%$ of participants indicated that they were 'very' or 'completely' satisfied with their involvement in the program.

\section{Sample Characteristics}

Characteristics of study sample are presented in Table 1. The mean age of the sample40.8 years with a range of 25 to 55 years. The majority of participants were married or living common-law (80\%) and had completed at least 12 years of education (93\%). The majority of participants were receiving salary indemnity at the time of enrolment. The sources of salary indemnity were as follows; work injury insurer $(30 \%)$, disability insurer (45\%), motor vehicle insurer (10\%), none (15\%). For all participants,

musculoskeletal pain was the primary diagnosis for which disability benefits were awarded. The majority of participants (91\%) reported that they had received physical therapy treatment at some point since their injury. Concurrent treatments included medication (for pain $=90 \%$, for depression $=45 \%$ ), physical therapy (30\%), occupational therapy $(27 \%)$, and psychotherapy $(20 \%)$.

Means and standard deviations on the MPQ-SF, PHQ-9 and PDI were similar (within one standard deviation) to those that have been reported in previous research on work-disabled individuals with comorbid pain and depression [41, 42]. Based on scores on the MPQ-SF and the PHQ-9, the study sample would be characterized as experiencing chronic pain of moderate severity, with moderately severe symptoms of depression at the time of admission.

\section{Treatment-Related Changes on Dependent Measures}

T-tests for paired samples were conducted to examine treatment-related changes in scores on measures of pain (MPQ-SF), depression (PHQ-9), self-reported disability (PDI), catastrophic thinking (PCS) and perceived injustice (IEQ). Means and standard deviations for assessments conducted at pre- and posttreatment are presented in Table 2. Analyses revealed significant reductions in scores on the MPQ-SF, $t$ $(53)=5.8, p<.001$ (medium effect size), the PHQ-9, t (53) = 7.0, $p<.001$ (large effect size), the PDI, t (53) 
$=4.8, p<.001$ (large effect size), the PCS, $t(53)=9.2, p<.001$ (large effect size), and IEQ, t (53) $=8.5, p<$ .001 (large effect size).

\section{Correlations Between Change Scores on Risk and Symptom Measures}

As shown in Table 3, reductions in the severity of symptoms of pain $(\triangle \mathrm{MPQ})$ and depression $(\triangle \mathrm{PHQ} 9)$ were significantly inter-correlated (large effect size). Consistent with previous research, reductions in catastrophic thinking ( $\triangle \mathrm{PCS}$ ) and perceived injustice $(\triangle \mathrm{IEQ})$ were also correlated with reductions in symptom severity (medium to large effect sizes) [22].

\section{Return to Work}

Participants were considered to have successfully returned to work if they were employed full- or parttime at 6-month follow-up. On the basis of this criterion, $57 \%$ of participants returned to work following participation in the treatment program. The majority $(78 \%)$ of participants who returned to work, returned to their pre-injury employment.

Table 4 shows the results of univariate tests of mean changes on dependent measures as a function of return-to-work outcomes. The results of these analyses revealed that participants who returned to work, compared to participants who remained absent from work, showed significantly greater reductions in pain severity, $\mathrm{t}_{\triangle \mathrm{MPQ}-\mathrm{SF}}(52)=2.6, \mathrm{p}=.01$, depression, $\mathrm{t}_{\triangle \mathrm{PHQ}-9}(52)=2.0, \mathrm{p}=.05$, catastrophic thinking,

$\mathrm{t}_{\triangle \mathrm{PCS}}(52)=3.6, \mathrm{p}=.001$, and perceived injustice, $\mathrm{t}_{\triangle \mathrm{IEQ}}(52)=3.2, \mathrm{p}=.001$.

Logistic regression was used to examine the value of treatment-related changes in symptom severity and psychosocial risk measures in predicting follow-up occupational status. In this analysis, age, sex, education and duration of work absence were entered in the first step as covariates. Change scores for measures of pain, depression, catastrophic thinking and perceived injustice were entered in the second step of the analysis. Tolerance coefficients for all variables included in the logistic regression analysis were greater than .60 indicating no problem of multicollinearity. Table 5 shows the Odds ratios from the final regression equation, $c^{2}(8)=43.2, p<.001$. As expected, age and education emerged as significant covariates, where older and less educated participants were less likely to return to work. Reductions in depression, catastrophic thinking and perceived injustice also emerged as significant unique predictors of return to work. Although reductions in pain distinguished between participants who did, and did not, return to work in univariate analysis, reductions in pain did not contribute significantly to the prediction of return to work in the logistic regression.

\section{Discussion}

The present study examined the acceptability and preliminary effectiveness of an RTBA intervention for work-disabled individuals with co-morbid pain and depression. The ultimate impact of any intervention program is determined in part by the degree to which individuals are agreeable to participate in it and successfully complete the intervention. In the present study, of 66 individuals who were invited to 
participate in the intervention, (90\%) agreed to view the introductory video and all individuals who viewed the introductory video agreed to enroll in the intervention program. Only 12 participants (18\%) discontinued the intervention program prematurely. Of the participants who completed the intervention, $91 \%$ indicated that they were 'very' or 'completely' satisfied with the treatment they received. These results suggest that the intervention was considered acceptable by the majority of study participants.

Participation in the intervention was associated with clinically significant reductions in pain severity (medium effect size), depression (large effect size) and self-reported disability (large effect size). These effect sizes for reductions in pain severity and self-reported disability are comparable to those that have been reported in work-disabled individuals with chronic musculoskeletal pain participating in pain management interventions [43-45]. The magnitude of reductions in PHQ-9 scores is comparable to that reported in clinical trials of behavioural activation therapy for patients with MDD [46, 47]. We were able to identify only one other study examining the effects of an occupational rehabilitation intervention for work-disabled individuals with co-morbid pain and depression, however the authors did not report treatment effects on pain, depression or self-reported disability [48].

To our knowledge this is one of only two papers to document the effects of a rehabilitation intervention for individuals with co-morbid pain and depression where return to work was a primary outcome variable. At 6-month follow-up evaluation, $57 \%$ percent of the study sample had resumed some form of employment. Ernsteen et al [48] reported $76 \%$ of participants with co-morbid pain and depression had returned to work after a 57-week multidisciplinary rehabilitation intervention. While yielding more positive return-to-work outcomes than the present study, it is important to consider that the costs associated with a 57-week multidisciplinary intervention would likely be unsustainable for many disability insurers and would likely be beyond the acceptable duration of treatment for many individuals. Ernsteen et al did not report data on acceptability of the rehabilitation program to the target population.

It is useful to compare the return-to-work outcomes of the present study with the return-to-work outcomes of rehabilitation interventions that have been offered to individuals with musculoskeletal pain of a similar level of chronicity, but without co-morbid depression. Poulin et al [49] reported that $55 \%$ of participants with chronic pain who completed a 4 week (120-hour) multidisciplinary rehabilitation intervention has resumed employment when assessed at 3-year follow-up. Brendbekken et al [50] reported that $45 \%$ of participants with chronic musculoskeletal pain had returned to work when assessed 12 months following completion of a multidisciplinary rehabilitation program. The results of several studies converge to suggest that multidisciplinary rehabilitation for individuals with chronic pain can be expected to yield return-to-work rates of approximately 50\% [51]. Given the data showing that depression markedly reduces the effectiveness of rehabilitation interventions for chronic pain, the $57 \%$ return-to-work outcome observed in the present study would be considered a favorable outcome for a population with co-morbid pain and depression.

In univariate analyses, reductions in pain severity, depression, catastrophic thinking and perceived injustice were associated with higher probability of return to work. In multivariate analyses, reductions in 
depression, catastrophic thinking and perceived injustice, but not pain, contributed significant unique variance to return-to-work outcomes. In previous research, depression, catastrophic thinking and perceived injustice have been identified as risk factors for delayed recovery in individuals with musculoskeletal pain $[23,52]$. These findings join a growing body of literature suggesting that targeting psychosocial risk factors such as catastrophic thinking and perceived injustice in the treatment of individuals with debilitating health or mental health conditions contributes to reductions in disability, beyond the variance accounted for by treatment-related reductions in symptom severity [16, 53-55].

Strengths of the treatment approach used in the present study was the use of a structured behavioral intervention originally developed for the treatment of depression, and inclusion of techniques specifically designed to reduce catastrophic thinking and perceived injustice. Another advantage of the treatment approach used in this study is the low cost of the intervention. RTBA is delivered by one clinician for a maximum of 10 direct contact hours. As such, the cost of treatment (approximately $\$ 1.5 \mathrm{k}$ ) is only a fraction of the costs associated with multidisciplinary treatment (range $\$ 10 \mathrm{k}-\$ 35 \mathrm{k}$ ). As well, the brief duration of training required to equip clinicians with the skills necessary to deliver RTBA is such that accessibility of the intervention can be readily scaled up to meet the treatment needs of the client population in any given region or jurisdiction. In the present study, clinicians (occupational therapists and physiotherapists) attended a two-day intensive training workshop to achieve competency in the delivery of the intervention, followed by weekly supervision for the duration of the trial. The duration of training required to achieve competency in the delivery of structured behavioral activation interventions is considerably shorter than what would be required to train allied health professionals in the delivery of other psychosocial interventions such as cognitive-behavior therapy (CBT).

Another advantage of the RTBA intervention used in the present study is that it can be offered as a treatment even when clients are being followed by a psychotherapist. A substantive proportion of workdisabled individuals with co-morbid pain and depression are likely to be referred to a mental health professional. Since the clinicians who delivered the RTBA intervention were not psychotherapists, there would rarely be occasion when the intervention could not be offered in combination with psychotherapy. The orientation of RTBA would be considered conceptually compatible with several psychotherapeutic orientations such as CBT, behavior therapy, and acceptance and commitment therapy. RTBA would be less conceptually compatible with psychotherapeutic orientations that have a more passive or palliative character.

There are several limitations to the present study that invite caution in the interpretation of the study findings. An important limitation was that the study did not include a control group. As well, given the pragmatic nature of the trial, participants continued with treatments that were prescribed by their treating physician. All participants were receiving some form of treatment for pain, depression or disability. Consequently, it is not possible to unambiguously attribute clinical outcomes to the effects of the RTBA intervention. However, most participants who were taking medication for pain or depression had been doing so for a considerable time before entering the trial, making it unlikely that the results could be attributed to the effects of pharmacological treatment. The present study operationalized mental health 
comorbidity on the basis of scores on self-report measures as opposed to structured diagnostic interview. Although the bulk of research on depression and pain following occupational injury has been conducted using self-report measures, the diagnostic interview is considered the gold standard for the diagnosis of mental health disorders. The modest sample size also limited the nature of analytic techniques that could be applied to the data. Greater confidence in advocating RTBA interventions for the treatment of workdisability associated with co-morbid pain and depression await the results of a randomized controlled trial.

It is also important to consider that the study sample might differ from the population of claimants of injury or disability insurers. Many insurers require that claimants participate in treatment to mitigate their losses, where refusal to enrol in prescribed treatments can have negative claim implications. Under these conditions, claimants of injury or disability insurers would not be considered 'volunteers'. Individuals who volunteer to enrol in a treatment program aimed at fostering occupational re-engagement might present with a higher degree of motivation and engagement than the typical claimant of an injury or disability insurer. This limitation however is not unique to the present study but is relevant to the interpretation and generalizability of all clinical trials using volunteers as participants.

Participants in the present study were offered financial compensation for the involvement in the intervention program. Financial compensation was offered to incentivise participation. Individuals with debilitating pain conditions are easily engaged in treatments that promise symptom-reduction, however, participant engagement in treatments that promise disability reduction or return to work is more challenging. Our pilot testing revealed very low interest in participating in a treatment program where the stated objective was return to work. While financial compensation for treatment participation would not be characteristic of the conditions under which treatment is typically offered, it is necessary to consider that treatment participation for individuals who are work-disabled due to a musculoskeletal problem is most often incentivized. Treatment referrals for problems contributing to work-disability are typically funded by injury insurers. Included in most injury insurance policies is a clause that requires the claimant to engage in treatment aimed at mitigating losses; failure to do so, particularly when the referral is initiated by the injury insurer, can have adverse claim consequences. Without some mechanism to incentivise participation, few individuals would be enrolling in disability reduction interventions.

In spite of limitations, the results of the present study provide preliminary evidence for the acceptability and effectiveness of RTBA as an approach to promoting successful occupational re-engagement in individuals with co-morbid pain and depression. The findings further suggest that treatment-related reductions in catastrophic thinking and perceived injustice might be important contributors to successful occupational re-engagement in individuals with co-morbid pain and depression. Return-to-work outcomes of individuals with co-morbid pain and depression might be enhanced by combining symptom management interventions with interventions specifically designed to reduce catastrophic thinking and perceptions of injustice. The finds warrant proceeding to a randomized clinical trial to assess the efficacy of RTBA as an approach to fostering occupational re-engagement in work-disabled individuals with comorbid pain and depression. 


\section{Declarations}

\section{Sources of financial support:}

This research was supported by funds from the Institut de recherche Robert-Sauvé en santé et en sécurité du travail (IRSST) and the Canada Research Chairs (CRC) Program.

\section{Conflict of Interest:}

The lead author generates revenue from clinical training workshops on risk-targeted behavioral activation.

\section{Name of Institutional Review Board:}

This study was approved by the Institutional Review Board of McGill University.

\section{Consent to participate:}

All participants provided informed consent.

\section{Consent for publication:}

All authors consent to publication.

\section{Acknowledgements}

The authors thank Monique Gagnon and Frederic Chappe for their assistance in data collection and data base management.

\section{Trial Registration}

Trial registration: ClinicalTrials.gov. Pending. Retrospectively registered.

\section{References}

1. Malik KM, Beckerly R, Imani F. Musculoskeletal disorders - a universal source of pain and disability misunderstood and mismanaged: A critical analysis based on the U.S. Model of Care. Anesth Pain Med. 2018;8(6):e85532. doi: 10.5812/aapm.85532.

2. Nieuwenhuijsen K, Verbeek J, de Boer AG, Blonk R, van Dijk FJH. Predicting the duration of sickness absence for patients with mental disorders in occupational health care. Scan J Work Environ Health. 2006;32(1):67-74.

3. Emptage NP, Sturm R, Robinson RL. Depression and comorbid pain as predictors of disability, employment, insurance status, and health care costs. Psychiatr Serv. 2005;56(4):468-74. doi: 10.1176/appi.ps.56.4.468. 
4. Currie S, Wang J. Chronic back pain and major depression in the general Canadian population. Pain. 2004;107:54-60.

5. Druss B, Rosenbeck R, Sledge W. Health and disability costs of depressive illness in a major US corporation. Am J Psychiat. 2000;157:1274-8.

6. Dozois $\mathrm{D}$, Dobson $\mathrm{K}$, Wong $\mathrm{M}$, Hughes $\mathrm{D}$, Long A. Factors associated with rehabilitation outcomes in patients with low back pain (LBP): Prediction of employment outcome at 9-month follow-up. Rehabil Psychol. 1995;40:243-59.

7. Schade V, Semmer N, Main C, Hora J, Boos N. The impact of clinical, morphological, psychosocial and work-related factors on the outcome of lumbar discectomy. Pain. 1999;80:239-49.

8. Glette M, Stiles TC, Jensen MP, Nilsen TIL, Borchgrevink PC, Landmark T. Impact of pain and catastrophizing on the long-term course of depression in the general population: the HUNT pain study. Pain. 2021;162(6):1650-8. doi: 10.1097/j.pain.0000000000002168.

9. Hung $\mathrm{Cl}$, Liu CY, Fu TS. Depression: An important factor associated with disability among patients with chronic low back pain. Int J Psychiatry Med. 2015;49(3):187-98. doi: $10.1177 / 0091217415573937$.

10. Kerns RD. Antidepressants combined with self-management of pain improves outcomes in people with comorbid pain and depression. Evidence-based mental health. 2010;13(1):13. doi: 13/1/13 [pii\} 10.1136/ebmh.13.1.13.

11. Rush AJ, Polatin P, Gatchel RJ. Depression and chronic low back pain: establishing priorities in treatment. Spine. 2000;25(20):2566-71.

12. Sullivan MJL, Reesor K, Mikail S, Fisher R. The treatment of depression in chronic low back pain: Review and recommendations. Pain. 1992;50:5-13.

13. Sullivan MD, Robinson JP. Antidepressant and anticonvulsant medication for chronic pain. Phys Med Rehabil Clinics North America. 2006;17(2):381-400, vi-vii.

14. Sullivan MJL. Emerging trends in secondary prevention of pain-related disability. Clin J Pain. 2003;19:77 - 9.

15. Millward LJ, Lutte A, Purvis RG. Depression and the perpetuation of an incapacitated identity as an inhibitor of return to work. J Psychiatr Ment Health Nurs. 2005;12(5):565-73. doi: JPM875 [pii] 10.1111/j.1365-2850.2005.00875.x.

16. Sullivan MJ, Adams H, Rhodenizer T, Stanish WD. A psychosocial risk factor--targeted intervention for the prevention of chronic pain and disability following whiplash injury. Phys Ther. 2006;86(1):8-18. doi: 10.1093/ptj/86.1.8.

17. Sullivan MJL, Scott W, Trost Z. Perceived injustice: a risk factor for problematic pain outcomes. Clin J Pain. 2012;28(6):484-8. doi: 10.1097/AJP.0b013e3182527d13.

18. Carriere JS, Thibault P, Sullivan MJ. The Mediating Role of Recovery Expectancies on the Relation Between Depression and Return-to-Work. J Occup Rehabil. 2015;25(2):348-56. doi: 10.1007/s10926014-9543-4. 
19. Arnow BA, Blasey CM, Constantino MJ, Robinson R, Hunkeler E, Lee J, et al. Catastrophizing, depression and pain-related disability. Gen Hosp Psychiatry. 2011;33(2):150-6. doi: 10.1016/j.genhosppsych.2010.12.008.

20. Martell CR, Dimidjian S, Herman-Dunn R. Behavioral activation for depression: A clinician's guide. New York: Guilford.; 2010.

21. Sullivan MJ, Thorn B, Haythornthwaite JA, Keefe F, Martin M, Bradley LA, et al. Theoretical perspectives on the relation between catastrophizing and pain. Clin J Pain. 2001;17(1):52-64. doi: 10.1097/00002508-200103000-00008.

22. Sullivan MJL, Adams H, Horan S, Maher D, Boland D, Gross R. The role of perceived injustice in the experience of chronic pain and disability: scale development and validation. J Occup Rehabil. 2008;18(3):249-61. doi: 10.1007/s10926-008-9140-5.

23. Sullivan MJL, Adams H, Martel MO, Scott W, Wideman T. Catastrophizing and perceived injustice: risk factors for the transition to chronicity after whiplash injury. Spine (Phila Pa 1976). 2011;36(25 Suppl):S244-9. doi: 10.1097/BRS.0b013e3182387fed.

24. Sullivan MJL, Adams H, Yamada K, Kubota Y, Ellis T, Thibault P. The relation between perceived injustice and symptom severity in individuals with major depression: A cross-lagged panel study. J Affect Disord. 2020;274:289-97. doi: 10.1016/j.jad.2020.05.129.

25. Carriere JS, Donayre Pimentel S, Yakobov E, Edwards RR. A Systematic Review of the Association Between Perceived Injustice and Pain-Related Outcomes in Individuals with Musculoskeletal Pain. Pain Med. 2020;21(7):1449-63. doi: 10.1093/pm/pnaa088.

26. Cuijpers P, van Straten A, Warmerdam L. Behavioral activation treatments of depression: a metaanalysis. Clin Psychol Rev. 2007;27(3):318-26. doi: 10.1016/j.cpr.2006.11.001.

27. Hellerstein DJ, Erickson G, Stewart JW, McGrath PJ, Hunnicutt-Ferguson K, Reynolds SK, et al. Behavioral activation therapy for return to work in medication-responsive chronic depression with persistent psychosocial dysfunction. Compr Psychiatry. 2015;57:140-7. doi:

10.1016/j.comppsych.2014.10.015.

28. Melzack R. The short-form McGill Pain Questionnaire. Pain. 1987;30(2):191-7. doi: 10.1016/03043959(87)91074-8.

29. Dudgeon D, Raubertas RF, Rosenthal SN. The short-form McGill Pain Questionnaire in chronic cancer pain. J Pain Symptom Manage. 1993;8(4):191-5. doi: 10.1016/0885-3924(93)90126-g.

30. Grafton KV, Foster NE, Wright CC. Test-retest reliability of the Short-Form McGill Pain Questionnaire: assessment of intraclass correlation coefficients and limits of agreement in patients with osteoarthritis. Clin J Pain. 2005;21(1):73-82. doi: 10.1097/00002508-200501000-00009.

31. Dutta D, Bharati S, Roy C, Das G. Measurement of prevalence of 'major depressive syndrome' among Indian patients attending pain clinic with chronic pain using PHQ-9 scale. J Anaesthesiol Clin Pharmacol. 2013;29(1):76-82. doi: 10.4103/0970-9185.105808.

32. Lowe B, Kroenke K, Herzog W, Grafe K. Measuring depression outcome with a brief self-report instrument: sensitivity to change of the Patient Health Questionnaire (PHQ-9). J Aff Dis. 2004;81:61 - 
6.

33. Sullivan MJL, Bishop SR, Pivik J. The Pain Catastrophizing Scale: Development and validation. Psychol Assessm. 1995;7:524 - 32.

34. Sullivan MJL, Stanish W, Waite H, Sullivan M, Tripp DA. Catastrophizing, pain, and disability in patients with soft-tissue injuries. Pain. 1998;77(3):253-60.

35. Osman A, Barrios FX, Gutierrez PM, Kopper BA, Merrifield T, Grittmann L. The Pain Catastrophizing Scale: further psychometric evaluation with adult samples. J Behav Med. 2000;23(4):351-65. doi: 10.1023/a:1005548801037.

36. Wheeler CHB, Williams ACC, Morley SJ. Meta-analysis of the psychometric properties of the Pain Catastrophizing Scale and associations with participant characteristics. Pain. 2019;160(9):1946-53. doi: 10.1097/j.pain.0000000000001494.

37. Tait RC, Pollard CA, Margolis RB, Duckro PN, Krause SJ. The Pain Disability Index: psychometric and validity data. Arch Phys Med Rehabil. 1987;68(7):438-41.

38. Tait RC, Chibnall JT, Krause S. The Pain Disability Index: psychometric properties. Pain. 1990;40(2):171-82.

39. Arroll B, Goodyear-Smith F, Crengle S, Gunn J, Kerse N, Fishman T, et al. Validation of PHQ-2 and PHQ-9 to screen for major depression in the primary care population. Ann Fam Med. 2010;8(4):34853. doi: 10.1370/afm.1139.

40. Levis B, Sun Y, He C, Wu Y, Krishnan A, Bhandari PM, et al. Accuracy of the PHQ-2 Alone and in Combination With the PHQ-9 for Screening to Detect Major Depression: Systematic Review and Meta-analysis. JAMA. 2020;323(22):2290-300. doi: 10.1001/jama.2020.6504.

41. Beneciuk JM, Bishop MD, Fritz JM, Robinson ME, Asal NR, Nisenzon AN, et al. The STarT back screening tool and individual psychological measures: evaluation of prognostic capabilities for low back pain clinical outcomes in outpatient physical therapy settings. Phys Ther. 2013;93(3):321-33. doi: 10.2522/ptj.20120207.

42. Warren AM, Jones AL, Bennett M, Solis JK, Reynolds M, Rainey EE, et al. Prospective Evaluation of Posttraumatic Stress Disorder in Injured Patients With and Without Orthopaedic Injury. J Orthop Trauma. 2016;30(9):e305-11. doi: 10.1097/BOT.0000000000000623.

43. Kamper SJ, Apeldoorn AT, Chiarotto A, Smeets RJ, Ostelo RW, Guzman J, et al. Multidisciplinary biopsychosocial rehabilitation for chronic low back pain. Cochrane Database Syst Rev. 2014(9):CD000963. doi: 10.1002/14651858.CD000963.pub3.

44. Semrau J, Hentschke C, Peters S, Pfeifer K. Effects of behavioural exercise therapy on the effectiveness of multidisciplinary rehabilitation for chronic non-specific low back pain: a randomised controlled trial. BMC Musculoskelet Disord. 2021;22(1):500. doi: 10.1186/s12891-021-04353-y.

45. Schmidt AM, Schiottz-Christensen B, Foster NE, Laurberg TB, Maribo T. The effect of an integrated multidisciplinary rehabilitation programme alternating inpatient interventions with home-based activities for patients with chronic low back pain: a randomized controlled trial. Clin Rehabil. 2020;34(3):382-93. doi: 10.1177/0269215519897968. 
46. Richards DA, Ekers D, McMillan D, Taylor RS, Byford S, Warren FC, et al. Cost and Outcome of Behavioural Activation versus Cognitive Behavioural Therapy for Depression (COBRA): a randomised, controlled, non-inferiority trial. Lancet. 2016;388(10047):871-80. doi: 10.1016/S01406736(16)31140-0.

47. Trombello JM, South C, Cecil A, Sanchez KE, Sanchez AC, Eidelman SL, et al. Efficacy of a Behavioral Activation Teletherapy Intervention to Treat Depression and Anxiety in Primary Care VitalSign6 Program. Prim Care Companion CNS Disord. 2017;19(5). doi: 10.4088/PCC.17m02146.

48. Ernstsen L, Lillefjell M. Physical functioning after occupational rehabilitation and returning to work among employees with chronic musculoskeletal pain and comorbid depressive symptoms. J Multidiscip Healthc. 2014;7:55-63. doi: 10.2147/JMDH.S55828.

49. Poulain C, Kerneis S, Rozenberg S, Fautrel B, Bourgeois P, Foltz V. Long-term return to work after a functional restoration program for chronic low-back pain patients: a prospective study. Eur Spine J. 2010;19(7):1153-61. doi: 10.1007/s00586-010-1361-6.

50. Brendbekken R, Eriksen HR, Grasdal A, Harris A, Hagen EM, Tangen T. Return to Work in Patients with Chronic Musculoskeletal Pain: Multidisciplinary Intervention Versus Brief Intervention: A Randomized Clinical Trial. J Occup Rehabil. 2017;27(1):82-91. doi: 10.1007/s10926-016-9634-5.

51. Wegrzynek PA, Wainwright E, Ravalier J. Return to work interventions for chronic pain: a systematic review. Occup Med (Lond). 2020;70(4):268-77. doi: 10.1093/occmed/kqaa066.

52. Moore E, Thibault P, Adams H, Sullivan MJL. Catastrophizing and pain-related fear predict failure to maintain treatment gains following participation in a pain rehabilitation program. Pain Rep. 2016;1(2):e567. doi: 10.1097/PR9.0000000000000567.

53. Sullivan MJL, Adams H, Ellis T, Clark R, Sully C, Thibault P. Treatment-related reductions in catastrophizing predict return to work in individuals with post-traumatic stress disorder. J Applied Behav Res. 2017(e12087). doi: 10.1111/jabr.12087.

54. Carriere JS, Thibault P, Milioto M, Sullivan MJL. Expectancies Mediate the Relations Among Pain Catastrophizing, Fear of Movement, and Return to Work Outcomes After Whiplash Injury. J Pain. 2015;16(12):1280-7. doi: 10.1016/j.jpain.2015.09.001.

55. Sullivan MJ, Adams H. Psychosocial treatment techniques to augment the impact of physiotherapy interventions for low back pain. Physiother Can. 2010;62(3):180-9. doi: 10.3138/physio.62.3.180.

\section{Tables}

\section{Table 1. Sample Characteristics}




$\begin{array}{lcc}\text { Variable } & \text { Men (N=51) } & \text { Women (N = l }) \\ \text { Age (years) } & 41.0(9.4) & 40.2(8.7) \\ \text { Education } & & \\ \quad \text { Less than high school } & 6(12 \%) & 2(14 \%) \\ \text { High school } & 22(43 \%) & 6(44 \%) \\ \text { College } & 14(27 \%) & 3(21 \%) \\ \quad \text { University } & 9(18 \%) & 3(21 \%) \\ \text { Injury Site } & & \\ \text { Back } & 40(78 \%) & 10(66 \%) \\ \text { Neck } & 11(22 \%) & 5(33 \%) \\ \text { Occupation } & & \\ \text { Labour } & 19(37 \%) & 0(0 \%) \\ \text { Trade } & 11(23 \%) & 0(0 \%) \\ \text { Health } & 9(17 \%) & 6(40 \%) \\ \text { Admin/clerical } & 5(9 \%) & 3(20 \%) \\ \text { Sales } & 3(6 \%) & 2(13 \%) \\ \text { Food/service } & 2(4 \%) & 2(13 \%) \\ \text { Education } & 2(4 \%) & 2(13 \%) \\ \text { Duration of work disability } & & \\ \text { 3-6 months } & 24(47 \%) & 5(33 \%) \\ 7-12 \text { months } & 18(35 \%) & 7(47 \%) \\ \text { More than 12 months } & 9(17 \%) & 3(20 \%) \\ \quad & \text { Mean (SD) } & \text { Mean (SD) } \\ \text { MPQ-SF (Pain) } & 21.3(10.5) & 22.1(10.5) \\ \text { PHQ-9 (Depression) } & 19.0(7.6) & 17.1(5.4) \\ \text { PDI (Disability) } & 40.3(13.4) & 38.3(19.6) \\ & & \end{array}$

Note: $\mathrm{N}=$ 66. PHQ-9 = Patient Health Questionnaire - 9; MPQ-SF = McGill Pain Questionnaire - Short Form; PDI = Pain Disability Index.

Table 2. Treatment-Related Changes in Dependent Measures

\begin{tabular}{|lrccr|}
\hline Variable & Pre-Treatment & Post-Treatment & \% change & \multicolumn{1}{c|}{$\boldsymbol{d}$} \\
\hline MPQ-SF & $21.5(9.8)$ & $14.0(8.4)$ & $-34.0 \%$ & .71 \\
\hline PHQ-9 & $18.5(7.2)$ & $11.7(7.3)$ & $-36.0 \%$ & .86 \\
\hline PDI & $37.0(15.8)$ & $20.9(13.2)$ & $-43.0 \%$ & .95 \\
\hline PCS & $29.6(9.2)$ & $17.8(9.9)$ & $-40.0 \%$ & 1.1 \\
\hline IEQ & $32.1(6.5)$ & $24.2(8.1)$ & $-25.0 \%$ & 1.0 \\
\hline
\end{tabular}

Note: N = 54. MPQ-SF = McGill Pain Questionnaire Short-Form; PHQ-9 = Patient Health Questionnaire; PDI = Pain Disability Index; PCS = Pain Catastrophizing Scale; IEQ = Injustice Experiences Questionnaire. $d=$ Cohen's $d$ (effect size). 
Table 3. Correlations Between Change Scores on Symptom Severity Measures and Psychosocial Risk Measures.

\begin{tabular}{|lccc|}
\hline & $\triangle$ MPQ-SF & $\triangle$ PHQ-9 & $\triangle$ PCS \\
\hline$\triangle$ MPQ-SF & & & \\
\hline$\triangle$ PHQ-9 & $.56^{\star \star}$ & & \\
\hline PCS & $.61^{\star \star}$ & $.43^{\star \star}$ & \\
\hline$\triangle$ IEQ & $.43^{\star *}$ & $.53^{\star *}$ & $.67^{\star \star}$ \\
\hline
\end{tabular}

Note: $\mathrm{N}=54 . \triangle \mathrm{MPQ}-\mathrm{SF}=$ Change on the McGill Pain Questionnaire Short-Form from pre- to posttreatment; $\triangle \mathrm{PHQ}-9=$ Change on the Patient Health Questionnaire -9 from pre- to post-treatment; $\triangle \mathrm{PCS}$ $=$ Change on the Pain Catastrophizing Scale from pre-to post-treatment; $\Delta$ IEQ = Change on the Injustice Experiences Questionnaire from pre- to post-treatment; ** $p<.01$.

Table 4. Mean Differences in Change Scores on Dependent Measures as a Function of Return-to-Work Outcomes.

\begin{tabular}{|lllll|}
\hline Return to Work & & & & \\
\hline Variable & No & Yes & P & $\boldsymbol{d}$ \\
& $(\mathrm{n}=23)$ & $(\mathrm{n}=31)$ & & \\
\hline$\Delta$ MPQ-SF & $3.0(9.6)$ & $10.7(11.4)$ & .01 & .73 \\
\hline$\triangle$ PHQ-9 & $5.4(6.4)$ & $9.4(7.4)$ & .05 & .58 \\
\hline$\triangle$ PCS & $5.6(11.1)$ & $14.8(9.5)$ & .001 & .89 \\
\hline$\triangle$ IEQ & $3.4(5.0)$ & $10.4(8.9)$ & .001 & .96 \\
\hline
\end{tabular}

Note: $\mathrm{N}=54 . \triangle \mathrm{MPQ}-\mathrm{SF}=$ Change on the McGill Pain Questionnaire Short-Form from pre- to posttreatment; $\triangle \mathrm{PHQ}-9=$ Change on the Patient Health Questionnaire -9 from pre- to post-treatment; $\triangle \mathrm{PCS}$ $=$ Change on the Pain Catastrophizing Scale from pre- to post-treatment; $\Delta$ IEQ $=$ Change on the Injustice Experiences Questionnaire from pre- to post-treatment; $* \star p<.01$.

Table 5. Logistic Regression Examining the Value of Changes in Symptom Severity and Psychosocial Risk Measures in Predicting Occupational Re-Engagement. 


\begin{tabular}{lccrcc} 
Variables & Wald & df & Sig & \multicolumn{1}{c}{ OR } & \multicolumn{1}{l}{$95 \% \mathrm{Cl}$} \\
\hline Age & 7.8 & 1 & .01 & .78 & $.65-.92$ \\
\hline Sex & 1.0 & 1 & .18 & 1.07 & $.51-13.15$ \\
\hline Education & 5.1 & 1 & .02 & 4.09 & $1.28-11.42$ \\
\hline Duration & .06 & 1 & .95 & .83 & $.27-3.99$ \\
\hline$\Delta$ MPQ-SF & .04 & 1 & .94 & .99 & $.86-1.14$ \\
\hline$\Delta$ PHQ-9 & 4.89 & 1 & .03 & 1.20 & $1.01-1.42$ \\
\hline$\Delta$ PCS & 5.24 & 1 & .04 & 1.23 & $1.03-1.48$ \\
\hline$\Delta$ IEQ & 4.80 & 1 & .02 & 1.29 & $1.03-1.64$
\end{tabular}

Note. $\mathrm{N}=54$. OR, odds ratio, $\mathrm{Cl}$, confidence interval, $\triangle \mathrm{MPQ}-\mathrm{SF}=$ Change on the McGill Pain Questionnaire Short-Form from pre- to post-treatment; $\triangle \mathrm{PHQ}-9=$ Change on the Patient Health Questionnaire -9 from pre- to post-treatment; $\Delta$ PCS $=$ Change on the Pain Catastrophizing Scale from pre- to post-treatment; $\Delta$ $\mathrm{IEQ}=$ Change on the Injustice Experiences Questionnaire from pre- to post-treatment. Odds ratios and associated significance tests are from the final regression equation.

\section{Supplementary Files}

This is a list of supplementary files associated with this preprint. Click to download.

- STROBEChecklist.docx 